\title{
Biodegradation of Different Types of Plastics by Tenebrio molitor Insect
}

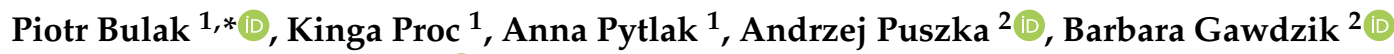 \\ and Andrzej Bieganowski ${ }^{1}$ (D)
}

1 Institute of Agrophysics, Polish Academy of Sciences, Doświadczalna 4, 20-290 Lublin, Poland; k.proc@ipan.lublin.pl (K.P.); a.pytlak@ipan.lublin.pl (A.P.); a.bieganowski@ipan.lublin.pl (A.B.)

2 Department of Polymer Chemistry, Institute of Chemical Sciences, Faculty of Chemistry, Maria Curie-Sklodowska University in Lublin, Gliniana 33, 20-614 Lublin, Poland; andrzej.puszka@umcs.pl (A.P.); barbara.gawdzik@poczta.umcs.lublin.pl (B.G.)

* Correspondence: p.bulak@ipan.lublin.pl

Citation: Bulak, P.; Proc, K.; Pytlak, A.; Puszka, A.; Gawdzik, B.; Bieganowski, A. Biodegradation of Different Types of Plastics by Tenebrio molitor Insect. Polymers 2021, 13, 3508 https://doi.org/10.3390/

polym13203508

Academic Editors: Antonio Pizzi and Beom Soo Kim

Received: 7 July 2021

Accepted: 8 October 2021

Published: 13 October 2021

Publisher's Note: MDPI stays neutra with regard to jurisdictional claims in published maps and institutional affiliations.

Copyright: (c) 2021 by the authors. Licensee MDPI, Basel, Switzerland. This article is an open access article distributed under the terms and conditions of the Creative Commons Attribution (CC BY) license (https:// creativecommons.org/licenses/by/ $4.0 /)$.

\begin{abstract}
Looking for new, sustainable ways to utilize plastics is still a very pertinent topic considering the amount of plastics produced in the world. One of the newest and intriguing possibility is the use of insects in biodegradation of plastics, which can be named entomoremediation. The aim of this work was to demonstrate the ability of the insect Tenebrio molitor to biodegrade different, real plastic waste. The types of plastic waste used were: remains of thermal building insulation polystyrene foam (PS), two types of polyurethane (kitchen sponge as PU1 and commercial thermal insulation foam as PU2), and polyethylene foam (PE), which has been used as packaging material. After 58 days, the efficiency of mass reduction for all of the investigated plastics was $46.5 \%, 41.0 \%, 53.2 \%$, and $69.7 \%$ for PS, PU1, PU2, and PE, respectively (with a dose of $0.0052 \mathrm{~g}$ of each plastic per 1 mealworm larvae). Both larvae and imago were active plastic eaters. However, in order to shorten the duration of the experiment and increase the specific consumption rate, the two forms of the insect should not be combined together in one container.
\end{abstract}

Keywords: mealworm; waste management; entomoremediation; bioremediation

\section{Introduction}

According to available data from 2019, worldwide plastic production reached $368 \mathrm{Mt}$ (mega tons). The largest amount of plastic was produced in Asia-51\% (of which China accounted for 31\%), followed by NAFTA countries (North America, Canada, Mexico) 19\%, Europe 16\%, Middle East, and Africa 7\%, Latin America 4\%, and Commonwealth of Independent States (CIS) countries 3\% [1]. In Europe, of the $29.1 \mathrm{Mt}$ of plastic waste collected in $2018,32.5 \%$ was recycled, $42.6 \%$ went to energy recovery, and $24.9 \%$ to landfills [1]. Although, as compared to 2016, in 2018 the annual average for recycling and energy recovery of plastic waste increased in Europe by $5.7 \%$ and $4.8 \%$, respectively, a significant proportion $(24.9 \%)$ still end its life cycle in landfills [1]. Furthermore, much of the plastic escapes waste collection systems, polluting the environment and entering the world's oceans. It was estimated that, e.g., in 2010, that of the $275 \mathrm{Mt}$ of plastic produced, as much as 4.8 to 12.7 Mt ended up in the aquatic environment [2]. Adequate waste management policies, as well as the improvement of the plastic waste management methods used, have a huge impact on the environment. In order to reduce the onerous problem of plastic waste, the European Commission has presented a plan which includes, among other things, allowing only reusable or recyclable plastic on the market and recycling at least half the amount of plastic produced [3].

Currently, various forms of recycling are used. This includes mechanical recycling, which involves re-introducing plastic waste into the production cycle and plasticizing it. All thermoplastics such as: polyethylene (PE), polypropylene (PP), and polystyrene (PS) 
are suitable for this procedure due to their ability to change shape under high temperature conditions. The disadvantage of this method is that plastics must be carefully sorted before recycling. However, it should be remembered that the food industry uses packaging of a high standard, so in most cases, recovered plastics must not be allowed to come into contact with food. Recycled materials usually go into the production of items of lower value (downcycling), such as garbage bags and traffic cones [4].

Chemical recycling includes activities connected with converting plastic waste into valuable chemical substances or into precursors of plastic. One of the ways can be by pyrolysis, where in anaerobic conditions under the influence of high temperatures and a catalyst plastics decompose, and which contributes to the production of biofuel [5]. Another chemical method is the gasification of plastics, the conversion of waste into gaseous products which can be used in the energy industry (it is necessary to control the level of chlorine content during this process) [6].

Another alternative way to reduce residual waste is to produce plastics capable of degradation under certain natural conditions, such as exposure to sunlight, moisture, having shorter composting times or types of plastics that can be degraded by living organisms. These plastics are called bioplastics, and include polyhydroxyalkanoates (PHA) and polylactide (PLA). Plastics made of petroleum-based polymers, such as PE, PP, PS are difficult to biodegrade. It was long thought that they are not available as carbon source for microbiota. Fortunately, it was found that some microorganisms possess the ability to produce enzymes that break down all these types of plastics $[7,8]$. The course of biodegradation is influenced by factors, such as the characteristics of the polymer itself (type of chemical bonds) and the storage conditions of the plastic waste. Biodegradation is highly anticipated and future-oriented natural method of plastic waste disposal [9].

There are many studies which show that some bacteria and fungi, especially those associated with the soil, are promising organisms for the biodegradation of plastic waste. The numerous examples include, e.g., the bacteria Brevibacillus borstelensis [10], Bacillus brevis [11], Pseudomonas stutzeri [12], and the fungi Rhizopus delemar [13], Mucor sp., Paecilomyces sp., and Thermomyces sp., [14], although more specific research is still needed on all of these, especially in order to increase their biodegradation potential.

Biodegradation potential has also been seen in more complex organisms, such as insects. T. molitor has the potential to consume PE, PS, PP, polyurethane (PU), polylactic acid (PLA), and polyvinyl chloride (PVC) [15-21] and even tire crumbs and vulcanized butadiene-styrene elastomer (SBR) rubber [22]. The biodegradability of PE and PS is provided by the larvae of the beetle Tribolium confusum [23] and the superworm Zophobas atratus [21]. Another example is Galleria mellonella, a wax moth, which is capable of PE degradation [24]. Studies have shown that the ability of the insect to biodegrade plastics is in most cases dependent on its intestinal microorganisms. For example, the fungus Aspergillus flavus contributed to PE degradation in the abovementioned wax moth [25]. However, studies on Corcyra cephalonica rice moth larvae have proven that they have the ability to degrade low density PE (LDPE) even after antibiotic therapy, indicating that biodegradation is not dependent on the activity of intestinal microflora enzymes [26]. These are examples of entomoremediation $[27,28]$ of plastics, a new subtype of bioremediation.

The recent discovery of the land snail Achatina fulica, able to disintegrate PS [29] regardless of the composition of the intestinal microflora, in our opinion is an outstanding example of how little we know about the enormous potential hidden in nature when it comes to the utilization of plastics.

T. molitor is a species of beetles from the Tenebrionidae family, found in temperate climate regions and considered a storage pest. T. molitor larvae is yellow, which is why it is commonly called a "yellow mealworm". Its size varies between 2.5 and $3.5 \mathrm{~cm}$. The adult form is black and measures approximately $1.5 \mathrm{~cm}$ [30]. Mealworm larvae are full of nutritional value, making them suitable as live animal feed, e.g., for the zoo industry [31,32]. They are also considered an alternative source of protein in the food industry [33,34]. T. molitor frass can be used as a substitute or additive for NPK fertilizers [35], but it can 
also be used to produce biogas through anaerobic digestion [36]. T. molitor itself is likely to have probiotic properties. Studies have shown that adding them to the diet of mice results in the growth of bacteria from the Bifidobacteriaceae and Lactobacillaceae families in their intestines [37]. Another study has found the enrichment of the beneficial intestinal microflora in rabbits, as well as a reduction in pathogens in their digestive tract [38]. T. molitor can also be a source of chitosan production, which can be used to produce UV-protective packaging due to its naturally opaque, brownish color [39].

The aim of the study was, therefore, test the performance of biodegradation of real plastic wastes by T. molitor, including polystyrene (PS), two types of polyurethane (PU) and polyethylene (PE) and, for the first time, provided data about the efficiency of polyurethane biodegradation by mealworms. To demonstrate how the process of plastics biodegradation by $T$. molitor really looks like we created time-lapse video. We measured also growth parameters of the insects in order to show how they performed on the wastes and discussed advantages and disadvantages of used approach. Heavy metals and other elements in plastics were also analyzed to see how their content affected the disposal of plastics by mealworms.

\section{Materials and Methods}

\subsection{Insect Rearing}

T. molitor larvae were ordered from an external supplier. The larvae were fed with wheat bran (KUPIEC, Poland). The dry weight (DW) of the bran was $87.92 \pm 0.01 \%$ $\left(105^{\circ} \mathrm{C} / 24 \mathrm{~h}\right)$ and $\mathrm{pH}_{\mathrm{H} 2 \mathrm{O}}=6.56 \pm 0.04(w / v$ 1:20). The mealworms were reared in the following conditions: temperature $24 \pm 1{ }^{\circ} \mathrm{C}$, relative humidity $60 \pm 5 \%$, in plastic containers at the Department of Natural Environment Biogeochemistry, Institute of Agrophysics PAS, Lublin, Poland. After the acclimatization of the larvae $(3 \mathrm{~d})$ they were sifted from wheat brans and left for $24 \mathrm{~h}$ to empty their intestines.

\subsection{Plastic Waste}

Four types of plastics were tested in the experiment:

1. Polystyrene (PS) in the form of Styrofoam, which is used for insulating building elevations;

2. Polyurethane foam (PU1) — in the form of kitchen sponges;

3. Polyurethane thermal insulation foam (PU2)—consisting of polyphenylpolyisocyanate polymethylene, according to information from the producer (SOUDAL Sp. z.o.o, Poland);

4. Polyethylene foam (PE) - which is used as filling material in packages, e.g., to protect electrical equipment during transport.

The plastic used is showed on Figure 1. Kitchen sponge (PU1) was used without the abrasive layer, which is often added to that type of houseware item. A day before the beginning of the experiment, PU2 was removed from the original packaging and left to bind in the form of one large mass. The following day, a thick slice was cut from the inside of this piece and was used in the experiment. All plastics were cut to obtain an equal weight of $2.6 \mathrm{~g}( \pm 0.001 \mathrm{~g})$ before the experiment begun, i.e., to match to the weight of the PU1 (kitchen sponge), which was taken as a whole

The original plan of the experiment assumed the use of only PS and two types of PU, but during the course of the experiment, we decided to add one more variant with PE foam, as there was no research on the possibility of PE foam biodegradation by mealworm larvae at that time. However, adding the PE variant was not possible in the experiment, which was just being filmed, so the time-lapse video shows only 3 types of plastic. 


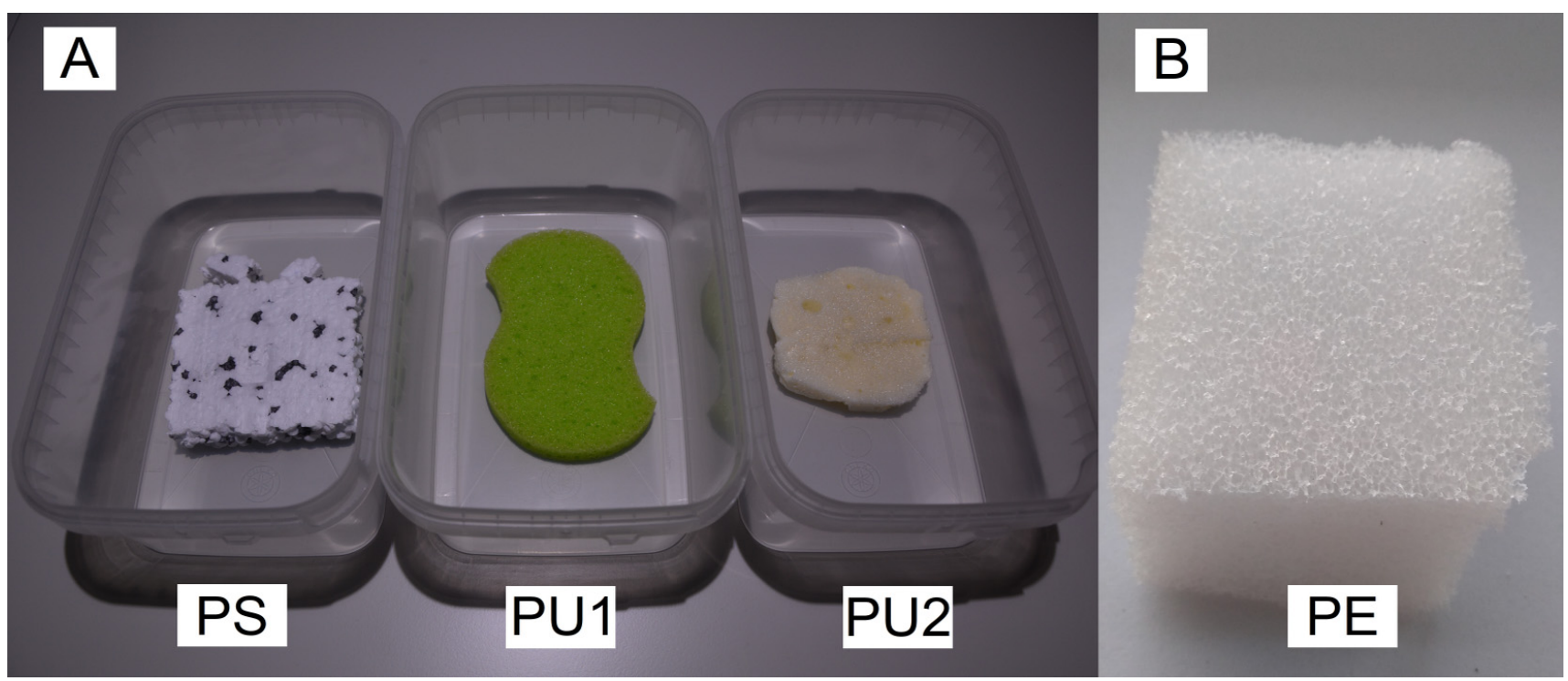

Figure 1. Plastics used for the experiment. (A) Materials for which time-lapse video was created. From left: polystyrene (PS), polyurethane kitchen sponge (PU1), polyurethane thermal insulation foam (PU2). (B) Polyethylene packaging foam (PE).

\subsection{Experimental Procedure}

Each of the four experimental variants was carried out in three independent replications in plastic boxes with dimensions of $30 \times 19 \times 12 \mathrm{~cm}$ (see Figure 1). The experiment was conducted in a laboratory room under controlled conditions: temperature $24 \pm 1{ }^{\circ} \mathrm{C}$ and relative humidity $60 \pm 5 \%$. Each container contained 500 mealworm larvae with a length and weight of individual larvae about $2.39 \pm 0.02 \mathrm{~cm}$ and $0.100 \pm 0.010 \mathrm{~g}$, respectively. All variants (PS, PU1, PU2, PE) included $2.6 \mathrm{~g}$ of a given plastic, therefore at the beginning of the experiment $0.0052 \mathrm{~g}$ of each plastic was available per 1 mealworm larvae (based on literature data and our preliminary trials). The substrates were not enriched with additional substances such as water or feed.

The substrates were weighed daily on a laboratory balance (OHAUS EX224M, Parsippany, NJ, USA) in order to investigate the loss of plastic. During the experiment, when the pupae started to appear massively, they were taken out of the container with tweezers and put into a separate glass vessel for pupation. After completion of this process, the adult beetles were once again moved back into the original container. This operation can be seen on the recorded Video S1. Adult beetles are also capable of eating plastics and can survive on this substrate as the sole source of food, similar to the larvae. As mealworm pupae are not mobile, removing the pupae during the experiment was performed in order to protect them from cannibalism by other developmental stages of the insect. Cannibalism, which is always present in mealworm breeding, would reduce the amount of eaten plastic.

The experiment lasted 58 days and was completed when the consumption of plastics by the insects became minimal. After that time the weight of the insects was determined by the use of a laboratory balance and their length using a hand ruler. In order to separate insect excrement from the uneaten plastic remains, they were sieved through a $500 \mu \mathrm{m}$ mesh size sieve.

The utilization rate $(\mathrm{U})$ of the plastics was calculated based on the following Equation (1):

$$
\mathrm{U}=\frac{m_{i}-m_{f}}{m_{i}} \cdot 100 \%
$$

where:

$m_{i}$-initial mass of plastic (i.e., at the beginning of the experiment) (g);

$m_{f}$-final mass of plastic (i.e., at the end of the experiment) $(\mathrm{g})$. 
Plastic remnants that passed through insect digestive tract were extracted from the mealworm frass collected after the experiment. One gram of the frass from each experimental variants was demineralized with $5 \% \mathrm{HCl}$ by $1 \mathrm{~h}$ in room temperature and then digested using $30 \% \mathrm{H}_{2} \mathrm{O}_{2}$ by $48 \mathrm{~h}$ in room temperature. Digestates were filtered on glass filter with pore size $1 \mu \mathrm{m}$ [40]. After that the samples were dried in $50^{\circ} \mathrm{C}$ for two days (until no mass changes were noticed).

\subsection{Fourier Transform Infrared Spectroscopy (FT-IR) of Plastics}

The FT-IR spectra were developed by applying attenuated total (internal) reflection (ATR/FT-IR) with the use of a FT-IR TENSOR 27 spectrophotometer (Bruker, Germany), complete with a PIKE measuring cell which features crystalline diamond embedded in zinc selenide. The FT-IR spectra were collected within the range of 4000 to $600 \mathrm{~cm}^{-1}$, with 32 scans per sample, at a resolution of $4 \mathrm{~cm}^{-1}$. The absorption mode was used for these measurements. Figure 2 showed spectra obtained for used materials.

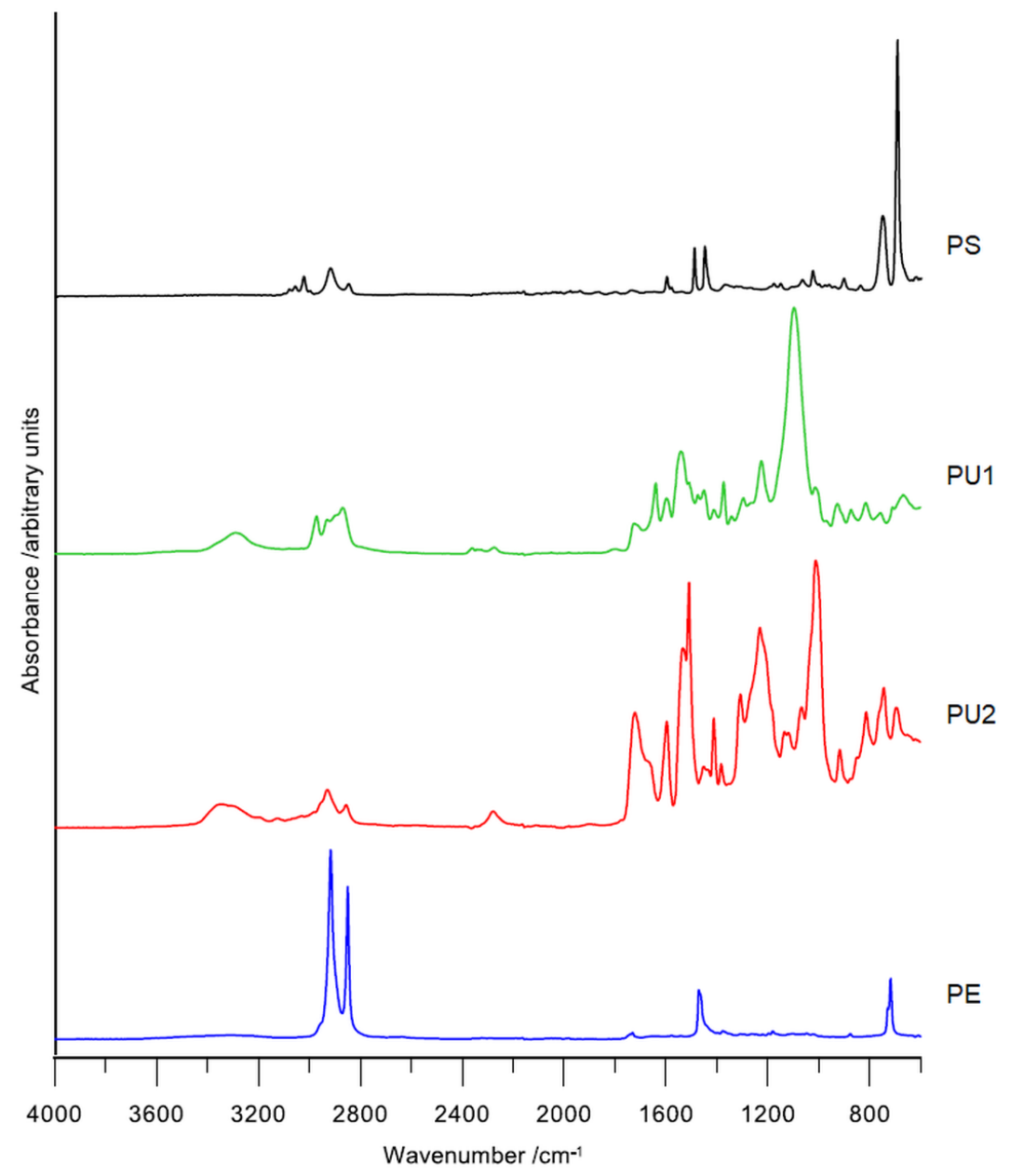

Figure 2. FT-IR spectra for plastics used in the experiments. PS-polystyrene (Styrofoam), PU1-polyurethane foam (kitchen sponge), PU2-polyurethane foam (building thermal insulator), PE-polyethylene foam (packaging foam).

The FT-IR spectra of the tested plastics are shown in Figure 2. The peaks at $2921 \mathrm{~cm}^{-1}$ and $2850 \mathrm{~cm}^{-1}$ correspond to $\mathrm{C}-\mathrm{H}$ asymmetric and symmetric stretching in $\mathrm{CH}_{2}$ groups. The presence of a benzene ring in PS is confirmed by absorption bands at $3060 \mathrm{~cm}^{-1}$ and $3026 \mathrm{~cm}^{-1}$ (correspond to $\mathrm{C}-\mathrm{H}$ stretching in benzene ring), band at $754 \mathrm{~cm}^{-1}$ corresponds to out-of-plane $\mathrm{C}-\mathrm{H}$ bending of the benzene ring. Absorption peaks at $1601 \mathrm{~cm}^{-1}, 1493 \mathrm{~cm}^{-1}$, 
$1452 \mathrm{~cm}^{-1}$ are related to $\mathrm{C}=\mathrm{C}$ stretching of the benzene ring. The absorption band at $696 \mathrm{~cm}^{-1}$ with high intensity corresponds to a monosubstituted benzene ring.

The FT-IR spectra of both polyurethane materials show characteristic absorption bands responsible for $\mathrm{N}-\mathrm{H}$ stretching vibrations (in the range 3290 to $3340 \mathrm{~cm}^{-1}$ ), N-H bending (at $1509 \mathrm{~cm}^{-1}$ ) and $\mathrm{C}=\mathrm{O}$ stretching (in the range 1727 to $1721 \mathrm{~cm}^{-1}$ ) of the urethane group and absorption bands at $2929 \mathrm{~cm}^{-1}$ and 2868 to $2855 \mathrm{~cm}^{-1}$ (asymmetrical and symmetrical, respectively) corresponding to $\mathrm{C}-\mathrm{H}$ stretching vibrations of the $\mathrm{CH}_{2}$ group, and at $1383-1373 \mathrm{~cm}^{-1}$ corresponding to $\mathrm{C}-\mathrm{C}$ bending vibrations.

The spectra of PE show characteristic absorption bands at around $2915 \mathrm{~cm}^{-1}$ and $2849 \mathrm{~cm}^{-1}$ connected to $\mathrm{C}-\mathrm{H}$ stretching in the $\mathrm{CH}_{2}$ group while absorption band at $1471 \mathrm{~cm}^{-1}$ correspond to $\mathrm{C}-\mathrm{H}$ bending in $\mathrm{CH}_{2}$ group. Absorption bands at $729 \mathrm{~cm}^{-1}$ and $718 \mathrm{~cm}^{-1}$ are connected to $\mathrm{C}-\mathrm{H}$ bending in-plane in $\mathrm{CH}_{2}$ groups.

\subsection{Energy Dispersive X-ray Fluorescence (EDXRF)}

The concentrations of elements in the plastics samples were measured by means of EDXRF using EDX-7000 (Shimadzu, Kioto, Japan). Measurements were completed in air atmosphere using default plastics measuring program with autobalance. Measurement time was $100 \mathrm{~s}$ on each channel and collimator had $10 \mathrm{~mm} \phi$. Samples were placed directly in the $\mathrm{Rh} \mathrm{X}$-ray beam without the use of foil or special containers.

\subsection{Scanning Electron Microscopy (SEM)}

Plastics samples taken for the experiment, as well as plastics remnants isolated from the insect frass after the experiment were sputter coated with a $30 \mathrm{~nm}$ Au layer in the coater EM ACE (Leica, Germany) and visualized by the use of Libra SEM (Carl Zeiss, Germany) set to the following parameters: work distance (WD) 9-15 mm; spot size 360-370, accelerating voltage $5 \mathrm{keV}$; aperture size $30 \mu \mathrm{m}$; beam current $30 \mu \mathrm{A}$; signal SE detector with scanning mode and pixel noise reduction.

\subsection{Photography and Time-Lapse Movie of Utilization}

Photography was completed with the use of a Nikon D7100 with an AF-D DX NIKKOR 18-105mm f/3.5-5.6G ED VR lens. Photographs were taken automatically every $30 \mathrm{~min}$ and a time-lapse movie was created from them using Adobe After Effects 2020 and Adobe Media Encoder 2020.

\subsection{Statistical Analysis}

Experimental results were analyzed using Statistica 13.1. The statistical significance was determined by t-Student test and ANOVA with post hoc Tukey's test $(p<0.05 ; \mathrm{n}=3)$. Three independent biological replications of the experiment were performed.

\section{Results}

\subsection{Rate of PS, PU1, PU2, and PE Consumption by Mealworms}

Figure 3 illustrates the weight reduction in plastics by T. molitor insect. The first significant (Student $t$-test, $p<0.05$ ) loss of mass for each type of plastic was observed on the third day of the experiment and amounted to $0.566,0.569,0.482$, and $0.313 \mathrm{~g}$ (PS, PU1, PU2, and $\mathrm{PE}$, respectively). On the 15th day, the most uniform utilization values of individual plastics were observed, ranging from 0.85 to $0.94 \mathrm{~g}$. On the 58th day of the experiment, statistically significant differences in the reduction mass of the plastics were shown and were as follows: PS $1.385 \mathrm{~g}$, PU1 $1.221 \mathrm{~g}$, PU2 $1.538 \mathrm{~g}$, and PE $1.818 \mathrm{~g}$, which is equivalent to a percentage loss of $46.93 \pm 0.12 \%, 46.77 \pm 2.73 \%, 58.97 \pm 5.15 \%$, and $69.71 \pm 6.34 \%$, respectively (Table 1) $(\mathrm{PE}>\mathrm{PU} 2>\mathrm{PS}>\mathrm{PU} 1)$. Interestingly, at the beginning, the utilization of PE was the lowest, however, it was ultimately the highest of all the plastics used in this trial. 


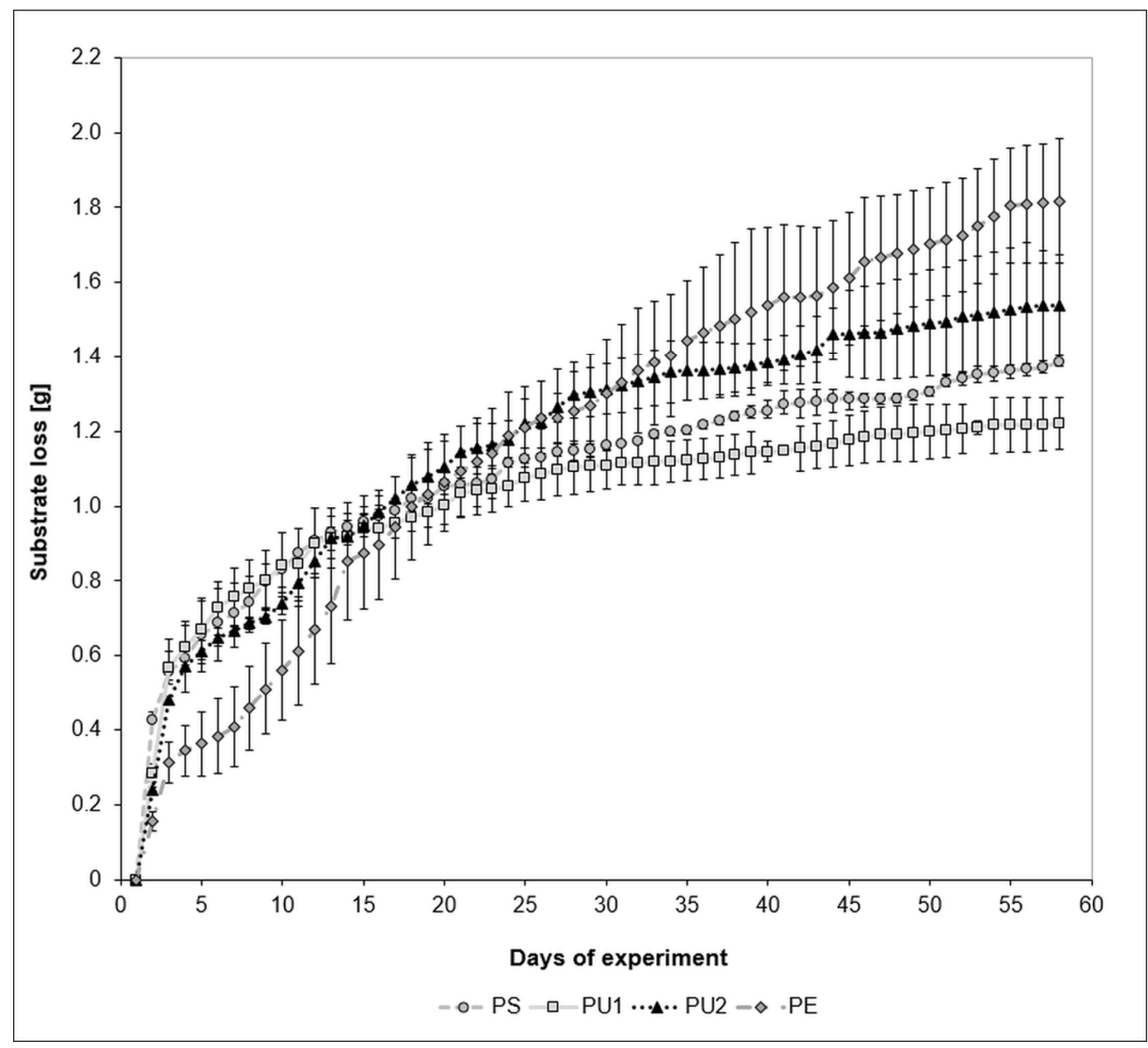

Figure 3. Cumulative loss of PS, PU1, PU2, and PE plastic waste (g) during feeding of T. molitor (mean $\pm \mathrm{SD} ; \mathrm{n}=3$ ).

Table 1. Weight of the plastics at the beginning and end of the experiment and the mass of plastics remnants in the mealworm frass (mean $\pm \mathrm{SD} ; \mathrm{n}=3$ ).

\begin{tabular}{|c|c|c|c|c|}
\hline Parameter $\backslash$ Plastic Type & PS & PU1 & PU2 & PE \\
\hline \multicolumn{5}{|c|}{ Initial } \\
\hline Mass of plastic [g] & $2.610 \pm 0.001$ & $2.611 \pm 0.001$ & $2.607 \pm 0.001$ & $2.608 \pm 0.001$ \\
\hline \multicolumn{5}{|c|}{ Final } \\
\hline Mass of plastic [g] & $1.225 \pm 0.004^{b, c, *}$ & $1.390 \pm 0.072^{c, *}$ & $1.070 \pm 0.133^{a, b, *}$ & $0.790 \pm 0.166^{a, *}$ \\
\hline Utilization $[w / w \%]$ & $46.929 \pm 0.124^{\mathrm{a}, \mathrm{b}}$ & $46.771 \pm 2.734^{\mathrm{a}}$ & $58.972 \pm 5.146^{\mathrm{c}}$ & $69.707 \pm 6.341^{\mathrm{c}}$ \\
\hline Plastic remnants in frass $[w / w \%]$ & $31.697 \pm 0.647^{\mathrm{a}}$ & $45.353 \pm 1.548^{\mathrm{d}}$ & $41.724 \pm 0.543^{\mathrm{c}}$ & $38.977 \pm 1.435^{b}$ \\
\hline
\end{tabular}

Significant differences between initial and final values of a given parameter are indicated with * (Student $t$-test, $p<0.05)$. Post hoc Tukey's test was completed to show significant differences between all the plastics within a given variable (different letters; $p<0.05$ ).

\subsection{Morphological Parameters of Mealworm Larvae}

Table 2 shows morphological parameters of T. molitor larvae. At the end of the experiment, the mass of 1 larvae in all variants, i.e., PS, PU1, PU2, PE decreased by $18.37 \%$, $28.28 \%, 26.26 \%$, and $24.71 \%$, respectively. Similarly, decrease in larvae length was also observed and amounted for PS 6.26\%, for PU1 9.35\%, for PU2 4.35\%, and for PE 6.58\% (Table 1). 
Table 2. Average length and fresh weight of the insects at the beginning and end of the experiment $( \pm S D ; n=3)$.

\begin{tabular}{|c|c|c|c|c|}
\hline Parameter $\backslash$ Substrate & PS & PU1 & PU2 & PE \\
\hline \multicolumn{5}{|c|}{ Initial } \\
\hline Mass of 1 larvae [g] & $0.098 \pm 0.001$ & $0.099 \pm 0.001$ & $0.099 \pm 0.001$ & $0.085 \pm 0.002$ \\
\hline Length of 1 larvae [cm] & $2.413 \pm 0.013$ & $2.397 \pm 0.060$ & $2.367 \pm 0.003$ & $2.386 \pm 0.047$ \\
\hline \multicolumn{5}{|c|}{ Final } \\
\hline Mass of 1 larvae [g] & $0.080 \pm 0.002^{b, *}$ & $0.071 \pm 0.003^{a, b, *}$ & $0.073 \pm 0.006^{a, b, *}$ & $0.064 \pm 0.001^{\mathrm{a}, *}$ \\
\hline Length of 1 larvae [cm] & $2.262 \pm 0.005^{\mathrm{a}, *}$ & $2.173 \pm 0.010^{\mathrm{a}, *}$ & $2.264 \pm 0.093^{\mathrm{a}}$ & $2.229 \pm 0.005^{\mathrm{a}, *}$ \\
\hline Mass of 1 adult [g] & $0.120 \pm 0.001^{b}$ & $0.114 \pm 0.008^{b}$ & $0.089 \pm 0.001^{\mathrm{a}}$ & $0.087 \pm 0.007^{\mathrm{a}}$ \\
\hline Length of 1 adult [cm] & $1.617 \pm 0.017^{b}$ & $1.450 \pm 0.050^{\mathrm{a}}$ & $1.459 \pm 0.092^{\mathrm{a}}$ & $1.322 \pm 0.006^{\mathrm{a}}$ \\
\hline
\end{tabular}

Significant differences between initial and final values of a given parameter are indicated with * (Student $t$-test, $p<0.05$ ). Post hoc Tukey's test was completed to show significant differences between all the plastics within a given variable (different letters; $p<0.05$ ).

\subsection{Elements Content in the Plastics}

Investigated plastics had in general trace amounts of different elements (Table 3), with some exceptions. PS had the highest concentration of $\mathrm{Br}$, amounted to $0.412 \pm 0.019 \%$. The samples of polyurethane kitchen sponge (PU1) was characterized by high concentration of $\mathrm{Ca}(10.110 \pm 0.301 \%), \mathrm{Al}(0.437 \pm 0.038 \%), \mathrm{Si}(0.358 \pm 0.027 \%)$, and $\mathrm{Cl}(0.224 \pm 0.022 \%)$. The second investigated polyurethane material (PU2) had different elemental composition and characterized by high content of $\mathrm{Cl}(7.574 \pm 0.141 \%)$ and $\mathrm{P}(1.379 \pm 0.035 \%)$. PE had only minor content of $\mathrm{Al}(0.180 \pm 0.029 \%)$ and $\mathrm{Ca}(1.381 \pm 0.020 \%)$. Interestingly in PS and PE trace amounts of Hf was detected.

Table 3. The concentrations of elements measured in plastics samples by means of EDXRF ( \pm SD; $\mathrm{n}=3)$.

\begin{tabular}{ccccc}
\hline \% & PS & PU1 & PU2 & PE \\
\hline A1 & - & $0.437 \pm 0.038$ & - & $0.180 \pm 0.029$ \\
\hline $\mathbf{B a}$ & - & - & - & $0.029 \pm 0.001$ \\
\hline $\mathbf{B r}$ & $0.412 \pm 0.019$ & - & $0.001 \pm 0.001$ & - \\
\hline $\mathbf{C a}$ & $0.020 \pm 0.009$ & $10.110 \pm 0.301$ & - & $1.381 \pm 0.020$ \\
\hline $\mathbf{C l}$ & $0.017 \pm 0.001$ & $0.224 \pm 0.022$ & $7.574 \pm 0.141$ & $0.017 \pm 0.004$ \\
\hline $\mathbf{C o}$ & $0.002 \pm 0.001$ & - & - & - \\
\hline $\mathbf{C r}$ & $0.003 \pm 0.001$ & $0.008 \pm 0.001$ & $0.001 \pm 0.000$ & $0.004 \pm 0.001$ \\
\hline $\mathbf{C u}$ & $0.006 \pm 0.000$ & $0.013 \pm 0.001$ & $0.001 \pm 0.000$ & $0.006 \pm 0.001$ \\
\hline $\mathbf{F e}$ & $0.008 \pm 0.002$ & $0.021 \pm 0.001$ & $0.001 \pm 0.000$ & $0.006 \pm 0.001$ \\
\hline $\mathbf{H f}$ & $0.010 \pm 0.001$ & - & - & $0.012 \pm 0.000$ \\
\hline $\mathbf{K}$ & $0.009 \pm 0.005$ & - & $0.004 \pm 0.002$ & $0.005 \pm 0.001$ \\
\hline $\mathbf{M n}$ & $0.003 \pm 0.001$ & $0.007 \pm 0.001$ & - & $0.002 \pm 0.000$ \\
\hline $\mathbf{N i}$ & - & $0.001 \pm 0.001$ & - & - \\
\hline $\mathbf{P}$ & - & - & $1.379 \pm 0.035$ & - \\
\hline $\mathbf{S}$ & $0.023 \pm 0.002$ & $0.008 \pm 0.005$ & - & $0.012 \pm 0.003$ \\
\hline $\mathbf{S i}$ & $0.049 \pm 0.005$ & $0.358 \pm 0.027$ & $0.072 \pm 0.004$ & $0.029 \pm 0.004$ \\
\hline $\mathbf{S n}$ & - & $0.070 \pm 0.000$ & - & - \\
\hline $\mathbf{T i}$ & - & $-0.003 \pm 0.000$ & - & $0.007 \pm 0.000$ \\
\hline $\mathbf{Z n}$ & $0.003 \pm 0.001$ & & & - \\
\hline
\end{tabular}




\subsection{Scanning Electron Microphotography of the Plastics Surfaces}

Figure 4 showed SEM microphotography taken from the plastic samples, which were used in the experiment and those which were isolated from the insect frass. At the beginning all materials were characterized by smooth surfaces. PS (Figure 4A) exhibited a smooth and delicately cross-linked surface structure with visible longitudinal cracks arranged in the same direction which were most likely caused by mechanical impact during sample preparation (breaking and cutting of brittle material). PS isolated from the frass showed completely different, rough and irregularly carved surface structure (Figure 4B). PUs foams (Figure 4C,E) structures were at the beginning also smooth but PU1 (Figure 4C) was more flat while PU2 (Figure 4E) showed a greater number of edges. After the passage of the digestive system of insects, the surface of the PU foams was significantly wrinkled (Figure $4 \mathrm{D}, \mathrm{F}$ ) and the edges clearly visible in the PU2 structure at the beginning were significantly smoothed. At the magnification of 20,000 $\times$ PE surface consisted of the flat valleys and flaky layers of material superimposed on one another with visible fine pores present in a small amount (Figure 4G). After digestion by the insect PE had undergone wrinkles, the pores were no longer visible and instead of them numerous small bubble-like protrusions have appeared (Figure 4H).

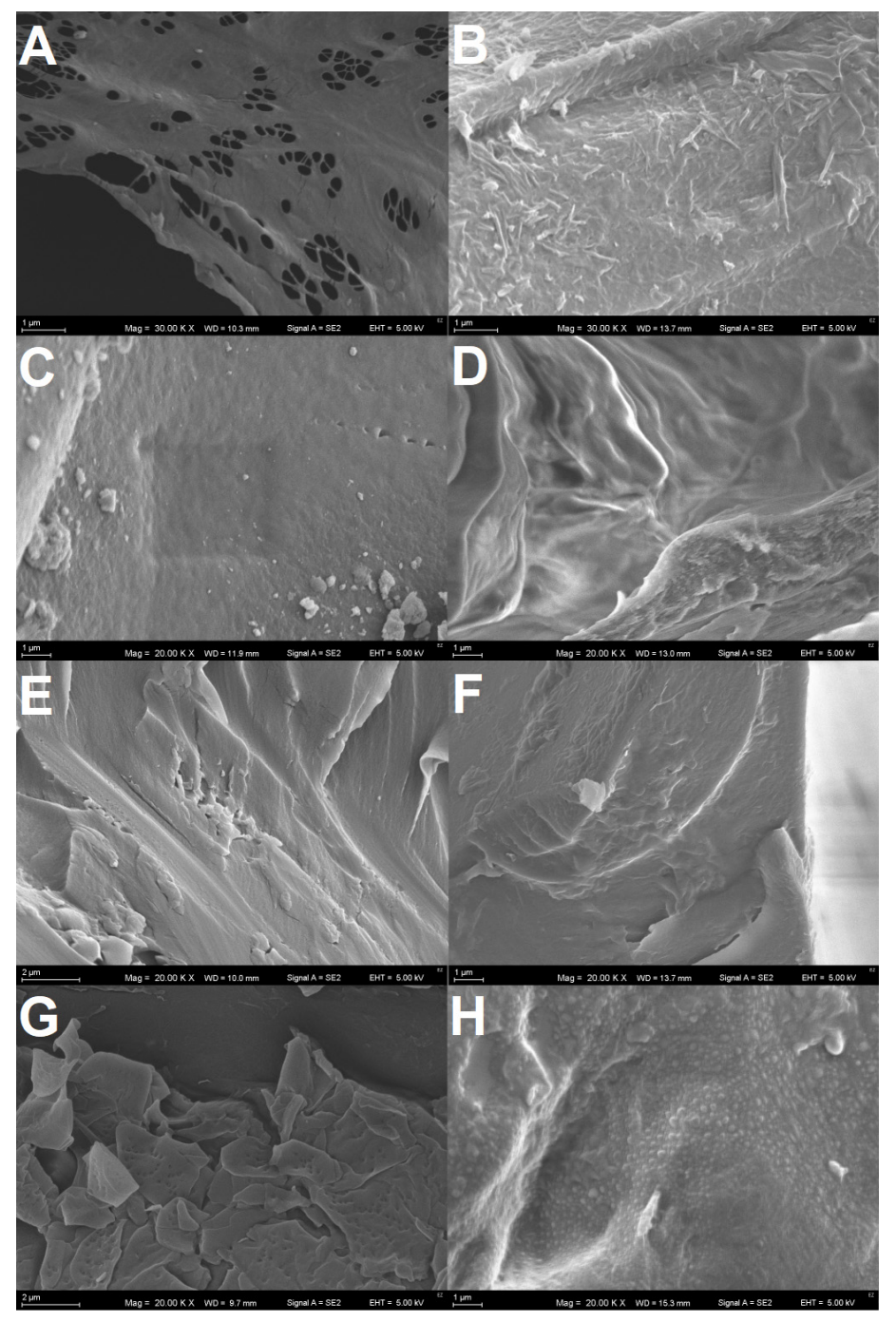

Figure 4. SEM microphotography of the plastic samples taken for the experiment $(\mathbf{A}, \mathbf{C}, \mathbf{E}, \mathbf{G})$ and plastics isolated from the insect frass after the experiment $(\mathbf{B}, \mathbf{D}, \mathbf{F}, \mathbf{H}) .(\mathbf{A}, \mathbf{B})$ : PS $(30,000 \times) ;(\mathbf{C}, \mathbf{D})$ : PU1 $(20,000 \times)$; (E,F): PU2 $(20,000 \times),(\mathbf{G}, \mathbf{H}):$ PE $(20,000 \times)$. Magnifications were selected to best illustrate the differences in the surface of the samples. 


\subsection{Time-Lapse Movie of Utilization}

Video S1 shows the setup used for this experiment. The initial mass of each plastic ( $2.6 \mathrm{~g})$ was adopted due to the weight of the PU1, which was a whole unused kitchen sponge. We tried to adjust the mass of the other plastics so that they were in one piece, but it was not always possible, and some required more material to be added (as seen in the example of PS). The sharp changes in the position of the plastic pieces visible in the video resulted from weighing them during the experiment in order to obtain data for Figure 3.

\section{Discussion}

\subsection{Rate of PS, PU1, PU2, and PE Consumption by Mealworms}

The results of PS have shown a higher degree of utilization compared to the studies of [16], where the reduction was only $9.0 \%$, and $[20,41]$, where the reduction was $31.0 \%$ and $39.1 \%$, respectively. Mealworms from three Chinese regions of Guangzhou, Tai'an, Shenzhen utilized $57.5 \%, 34.4 \%$, and $52.4 \%$ of PS, respectively [19]. In the study [42], authors used two mealworm species (T. molitor and T. obscurus) and reached $41.5 \%$ and $55.4 \%$ of PS utilization. They also found that the application of food additives in the form of wheat bran for T. molitor and corn flour for T. obscurus resulted in increased PS utilization: $56.8 \%$ and $67.1 \%$, respectively. A similar increase was obtained by [43], where the addition of wheat bran to PS increased the utilization rate from $31.7 \%$ PS to $54.4 \%$.

To our best knowledge there are no reports about the efficiency of PU utilization by mealworm. The researchers [44] investigated the epigenetic modification of mitochondrial DNA in T. molitor caused by PU as a sole source of feed, however they did not present any utilization parameters. Others [45], applied another insect species, Zophobas morio, from the same family as T. molitor (Tenebrionidae) to utilize PU, but the degradation was only $6 \%$. Our results showed a remarkably higher efficiency. Utilization of PU1 (kitchen sponge) and PU2 (commercial insulation foam) (Figure 3, Table 1) amounted to $46.8 \%$ and $59.0 \%$, respectively. This significant difference between both materials was probably caused by the different chemical composition (Figure 2) and, hence, its different macrostructure and properties (e.g., hardness). PU1 was soft and elastic, while PU2 was rigid and brittle. The observations show that regardless of the material itself, it is much easier for mealworms to bite and chew something that is stiff and brittle than flexible and soft. FTIR spectra showed the presence of different additives in both PUs (Figure 2), while element content analysis (Table 3) allow to deduce to which classes of chemical compounds these additives can belong (discussion below, see Section 4.3). Moreover, FTIR spectra confirmed that PU1 was soft PU due to the presence of the $1120 \mathrm{~cm}^{-1}$ band characteristic for aliphatic alcoxy-groups (Figure 2). PU2 was rigid foam due to presence of the band around 1600, 100, and $650 \mathrm{~cm}^{-1}$, which confirmed ring structure of PU2 formulation (Figure 2). The spectrum showed also 2 characteristic bands at 1250 and $1040 \mathrm{~cm}^{-1}$, which indicated the aromatic alkoxy-groups (Figure 2). Soft foams are formed of polyols with a molecular weight of 2000 to 8000 units and diisocyanates, while rigid foams are made of polyols with a molecular weight of less than 1000 units and a mixture of di- and triisocyanates. Summarizing, the differences in the utilization of PU1 and PU2 resulted from the different chemical composition of both materials, as well as the difference in mechanical properties. The results obtained for PE reduction were higher than the results presented in the literature. [19] exploited the mealworm larvae for PE disposal and showed that the origin of the larvae (different regions in China) influenced the degree of utilization. The results were: $36.9 \%$ loss of PE for the larvae from Guangzhou, $22.0 \%$ for larvae taken from Tai'an, and $29.7 \%$ for larvae from Shenzhen. These differences were probably caused by the different microbiomes inhabiting the intestines of the larvae. The addition of wheat bran increased the degradation rate of PE from $48.3 \%$ to $61.1 \%$ [ 43$]$.

It must be mentioned that not $100 \%$ of the eaten amount of given plastic is assimilated by the mealworms. As revealed by [20], $47.7 \%$ of ingested PS carbon was converted to $\mathrm{CO}_{2}$ and ca. $0.5 \%$ was assimilated into biomass (lipids). This indicated that ca. 50\% of PS left in the frass [20]. Our results showed that the total amount of the plastics remnants in the 
mealworm frass was in the range of $31.7 \%$ to $45.4 \%$ (Table 1). PS was the most susceptible to biodegradation while PU1 the least. The relatively high presence of plastics in the feces is disadvantageous due to the possibility of spreading microplastics, however research is needed on the susceptibility of these residues to microbial degradation, as it can be changed due to the action of enzymes in the insects digestive tract.

Table 4 showed specific consumption rate given as $\mu$ g plastic $\cdot$ day $^{-1} \cdot \operatorname{larvae}^{-1}$ calculated for our results, as well as for literature data. In most of the articles, the experiments were conducted for 30 days, therefore to calculate this parameter we used our data for plastic waste utilization also for that day. In general, specific consumption rate for PS as reported in the literature was within the range of 118.0 to $268.2 \mu \mathrm{g}$ plastic $\cdot$ day $^{-1} \cdot$ larvae $^{-1}$ (Table 4) and can be enhanced by the addition of more natural and nutritious feed, such as soy protein, up to $491.0 \mu \mathrm{g}$ plastic. day ${ }^{-1} \cdot$ larvae $^{-1}$ [46]. PE consumption rates were in the lower range than PS: 102.7 to $226.6 \mu \mathrm{g}$ plastic $\cdot$ day $^{-1} \cdot$ larvae $^{-1}$ (Table 4) and was increased to $286.5 \mu \mathrm{g}$ plastic. day $^{-1} \cdot$ larvae $^{-1}$ by the addition of wheat bran [47]. Lower than reported so far consumption rates calculated for our results were the consequence of experiment design, in which both larvae and adult insects were used in one container to eat plastics. This increased the chance of cannibalism occurring. The second reason was the early appearance of pupae (which can be clearly seen in Video S1), which excluded a large number of insects from actively eating plastic during pupation. Pupae started to appear in large numbers starting from day 10. Specific consumptions rate calculated for this day fall within the range reported in the cited literature (Table 4).

Table 4. Plastic consumption rates calculated on the basis of literature data and from this publication.

\begin{tabular}{|c|c|c|}
\hline Plastic & Consumption Rate $\left[\mu\right.$ g. day ${ }^{-1} \cdot$ larvae $\left.^{-1}\right]$ & Literature \\
\hline \multirow{6}{*}{ Polystyrene (PS) } & $\begin{array}{l}\text { T. molitor from Guangzhou: } 268.3 \\
\text { T. molitor from Tai'an: } 160.5 \\
\text { T. molitor from Shenzhen: } 239.9\end{array}$ & [19] \\
\hline & 119.9 & [20] \\
\hline & $\begin{array}{l}\text { T. molitor, PS alone: } 243.0 \\
\text { T. molitor, PS + wheat bran: } 332.3 \\
\text { T. obscurus, PS alone: } 324.4 \\
\text { T. obscurus, PS + corn flour: } 392.4\end{array}$ & {$[40]$} \\
\hline & $\begin{array}{l}\text { PS alone: } 118.0-222.0 \\
\text { PS + soy protein: } 491.0 \\
\text { PS + wheat bran: } 441.0\end{array}$ & [46] \\
\hline & $\begin{array}{c}\text { PS alone: } 148.4 \\
\text { PS + wheat bran: } 255.2\end{array}$ & [47] \\
\hline & $\begin{array}{r}77.4^{\mathrm{a}} \\
174.7^{\mathrm{b}}\end{array}$ & This research $^{a}$ \\
\hline Polyurethane (PU) & $\begin{array}{l}\text { PU1: } 73.9^{\mathrm{a}} \\
168.7^{\mathrm{b}} \\
\text { PU2: } 87.5^{\mathrm{a}} \\
158.9^{\mathrm{b}}\end{array}$ & This research $^{a}$ \\
\hline \multirow[t]{3}{*}{ Polyethylene (PE) } & $\begin{array}{l}\text { T. molitor from Guangzhou: } 172.2 \\
\text { T. molitor from Tai'an: } 102.7 \\
\text { T. molitor from Shenzhen: } 138.6\end{array}$ & [19] \\
\hline & $\begin{array}{c}\text { PE alone: } 226.6 \\
\text { PE + wheat bran: } 286.5\end{array}$ & [47] \\
\hline & $\begin{array}{c}86.7^{\mathrm{a}} \\
122.4^{\mathrm{b}}\end{array}$ & This research $^{\mathrm{a}}$ \\
\hline
\end{tabular}

a-calculated from the weight loss data of the given plastic on the 30th day of the experiment (Figure 3). $\mathrm{b}$-calculated from the weight loss data of the given plastic on the 10th day of the experiment (Figure 3 ). 
Genetic differences between mealworm populations around the globe can be the third reason. As shown in [19], genetic differences can be significant even between national populations.

From our results it can be estimated how many mealworm insects (in terms of pieces and mass) would be needed to utilize $1 \mathrm{~kg}$ of each waste plastic in the same time as in the presented experiment (i.e., 58 days). During the experiment, 500 insects consumed $1.385 \mathrm{~g}$ of PS, $1.221 \mathrm{~g}$ of PU1, $1.537 \mathrm{~g}$ of PU2, and $1.818 \mathrm{~g}$ of PE. Approximating directly, the following number of insects would be needed: 361,011 pc. for PS, 409,500 pc. for PU1, 325,309 pc. for PU2, and 275,028 pc. for PE. The average mass of 500 pc. of larvae we used for the experiment was $56.166 \mathrm{~g}$. Therefore, in terms of mass, one would need the following number of mealworms for the utilization of $1 \mathrm{~kg}$ of PS, PU1, PU2, PE during 58 days: $40.5 \mathrm{~kg}, 46.0 \mathrm{~kg}, 36.5 \mathrm{~kg}$, and $30.9 \mathrm{~kg}$, respectively. Such amounts are currently commercially available from large growers.

\subsection{Morphological Parameters of Mealworm Larvae}

Different studies reported different changes in mass. A decrease in the average weight of T. molitor larvae fed with PS differed greatly between the larvae from different sources and amounted to 3.31\%, 21.70\%, and 37.06\% for Guangzhou, Tai'an, and Shenzhen, respectively [19]. Similar results were obtained by [42], where the reduction in T. molitor larvae weight was $8.6 \%$ on PS. However, in the study of [41], no significant changes in weight of larvae fed with PS were observed. Contrary, a weight increase of $2.5 \pm 1.0 \%$ was observed by [46] for expanded PS.

Decrease in the mass of mealworm larvae fed with PE, which amounted to $1.03 \%$, $22.10 \%$, and $24.87 \%$ was also noticed for the abovementioned Chinese regions, respectively [19]. Ref. [46] used two types of PE: PE1, which had added pink colorant and PE2, which was without colored additives. On the first material, an $8.8 \pm 2.1 \%$ increase in larval weight was observed and on the second one a decrease of $3.4 \pm 1.6 \%$. This allows to conclude that differences may at least be partially dependent on additives for plastics, such as colorants and fillers.

Unfortunately, the cited research did not present the changes in insect length. Literature data [20] suggested that, most likely, the insects lose some of the fat tissue they had before the experiment and the hydration level of their bodies decreases significantly. This is because, in the studies, plastics were usually the only source of food and larvae had no access to water. Recently, ref. [47] showed that mealworm fed with polystyrene did indeed have a lower fat content than those who ate a conventional diet. Amazingly, they were still capable of successful pupation, which indirectly proves that digestion and assimilation must occurred.

\subsection{Elements in the Plastics}

To check whether differences in the content of elements may affect the utilization of plastics by mealworm larvae, their content was examined. Not even trace amounts of toxic heavy metals, such as $\mathrm{Cd}, \mathrm{Hg}$, or $\mathrm{Pb}$, were identified in any of the samples. The majority of elements were present only in trace amounts (much below $0.1 \%$ ).

Among all 13 identified elements in PS samples, only Br had non-trace concentration of $0.4 \%$. The compound containing $\mathrm{Br}$, which are added to plastics fall into class of flame retardants (FR) and green and red pigments [48,49]. The presence of $\mathrm{Br}$ can be connected with the addition of, e.g., hexabromocyclododecane, which is widely utilized FR in the formulations of PS [48]. Kitchen sponge (PU1) had the highest concentration of $\mathrm{Ca}$. Ca in plastics serves, mainly, as a filling and reinforcement agent, which is added in the form of $\mathrm{CaCO}_{3}$ [48]. PU1 had also ca. $0.6 \% \mathrm{Si}$, which indicated that $\mathrm{Ca}$ may have been partially added as wollastonite $\left(\mathrm{CaSiO}_{3}\right)$ or other $\mathrm{Si}$ compounds, which improved FR properties of the plastic [50]. The content of $\mathrm{Cl}$ in PU1 may be connected with the addition of green Cl-based pigments, chemically belonging to chlorinated/brominated phthalocyanine compounds [48]. Additionally, Cl-containing compounds, such as, e.g., Triclosan, could be added to PUs as antimicrobial agents [48]. Much higher content of 
$\mathrm{Cl}$ found in PU2 altogether with $1.4 \% \mathrm{P}$ may be the result of using as FRs chlorinated alkyl phosphates [49], such as, e.g., tris(1-chloro-2-propyl) phosphate and tris-2-chloroethyl phosphate; such compounds are used in rigid and flexible PU foam formulations [48]. PU1 had also elevated concentration of Al. The compounds of these element are used, i.e., as stabilizers and FR but in much higher concentrations, therefore the presence of Al in PU1 was probably due to the use of Al-based fillers [48].

The presence of $\mathrm{Ca}$ in PE was the most likely connected with the inorganic filler added to the plastic to enhance its strength and decrease the cost of production, while low amount of Al may result from the use of compounds, such as mica or kaolin to surface stabilization of the material [48].

Analysis showed trace amount of quite exotic Hf metal in PS and PE samples. In PE it can be connected with the use of catalyst based on Hf metallocene compounds, which are widely used in the production of polyolefins [51]. In PS, it can be the results of contamination during production of this plastic by a manufacturer, which also produced polyolefins.

Figure S1 showed concentration of elements in the larvae after the experiment determined by EDXRF. Regardless of the variant, major mineral components of the larvae were $\mathrm{K}, \mathrm{Cl}, \mathrm{P}(>1 \%)$ and $\mathrm{S}(1-0.5 \%)$. Ca was present in concentrations of $0.1 \%, \mathrm{Zn}$ and Fe in the order of $0.02-0.01 \%$ and $\mathrm{Cu}$ below $0.01 \%$. Non-physiological elements present in the plastics probably not affected the mealworms due to its low concentrations.

\subsection{Polymers Surface Alterations Visualized by SEM}

Surface alterations of the plastics are characteristic of the aging processes occurring under the influence of microorganisms (present in the intestines of insects) or, more specifically, enzymes secreted by them. The folding of the previously smooth surface of the polymer and the formation of pitting was observed during the biodegradation of PS and PE with the bacterium P. aeruginosa isolated from the gut of Zophobas morio insect (Tenebrionidae; cousin of mealworm, known also as superworm) [52]. Surface elements mapping comparison of PS and PE before and after biodegradation showed that those changes were connected with increase in oxygen content, which suggests oxidative changes in the plastics [52]. Similar changes as observed by us in the case of PU foams had been observed by [53] after biodegradation trials in soil burial. SEM surface microphotography (Figure 4) was indirect proof that plastics eaten by the mealworm biodegraded during the action of microorganisms enzymes, as well as enzymes secreted by mealworms itself.

\subsection{Time-Lapse Movie of Biodegradation}

It can be seen that during the experiment, pupae started to appear quite quickly, especially on PU1 (Video S1). It was about 10 days after experiment had started. At the beginning, we had not planned to pull out the pupae but it became obvious that without this step the degradation of the plastics would be lowered due to the cannibalistic behavior of the larvae. This is a known problem in mealworm breeding, especially when the insects have limited access to water and a low protein content in the substrate [54]. One of the aims of this study was to reach as a high a utilization of plastics as possible, therefore we decided to take advantage of the adults' ability to feed on plastics as well. When the amount of the adult insects increased in the containers, cannibalism started to occur with the larvae being the victim. It can be seen in the second part of the Video S1, adults formed specific "bundles" for a while with eaten larvae inside it. During the experiment dead adults were taken out the of the containers to prevent the larvae from preferring them as food. Our observations suggests also that the lifespan of the adults was much shorter than it would have been on optimal feed. Video S1 suggested that the adults' ability to consume plastic can also be useful but they should not be combined with earlier stages within the one container to prevent cannibalism and decrease the utilization of plastics. 


\section{Conclusions}

The efficiency of mass reduction for all of investigated plastics was $46.5 \%, 41.0 \%$, $53.2 \%$, and $69.7 \%$ for PS, PU1, PU2, and PE, respectively. However, specific consumption rates for each plastics was lower that calculated from literature data. This was due to the large number of pupae appearing less than two weeks after the start of the experiment and the combination of larvae with adults in one container, which resulted in cannibalistic behavior. Additionally, the used plastic waste were characterized by the addition of fillers and FRs, which may influenced consumption rates. The utilization of plastics can be increased by removing pupae from larvae and imago and by not combining adult and larval forms in one container. Both larvae and imago were active in the eating of plastics. More research is needed on different optimization approaches, which would reduce the number of insects used while maintaining process efficiency. Such optimization should be completed in order to decrease the costs of entomoremediation for larger amounts of plastics. The risk of spreading microplastics with insect feces which left after this process should also be determined in the future research.

Supplementary Materials: The following are available online at https: / www.mdpi.com/article/ 10.3390/polym13203508/s1, Figure S1: Element contents in T. molitor larvae after the experiment, Video S1: Time-lapse movie of the process of plastics waste entomoremediation by Tenebrio molitor.

Author Contributions: P.B.: Conceptualization, Methodology, Formal analysis, Investigation, Writing—original draft, Writing—review and editing, Supervision, Funding acquisition, Project administration. K.P.: Investigation, Methodology, Writing—original draft. A.P. (Anna Pytlak): Methodology, Writing—original draft. A.P. (Andrzej Puszka): Methodology, Investigation, Writing—original draft. B.G.: Methodology, Supervision. A.B.: Methodology, Supervision. All authors have read and agreed to the published version of the manuscript.

Funding: This research was partially founded by the National Science Centre, Poland, grant number 2019/35/D/NZ9/01835. The APC have been granted by MDPI.

Institutional Review Board Statement: Ethical review and approval were waived for this study, as the use of invertebrate animals, like insects, for laboratory experiments do not require approval of bioethics committees and are not subject to procedures in accordance with Directive 2010/63/EU of the European Parliament and of the Council of 22 September 2010 on the protection of animals used for scientific purposes, amended by Regulation (EU) 2019/1010 of the European Parliament and of the Council of 5 June 2019 as well as Polish National Act of 15 January 2015 on the protection of animals used for scientific or educational purposes.

Informed Consent Statement: Not applicable.

Data Availability Statement: Data may be provided upon request to the corresponding author.

Acknowledgments: The authors wish to thank Katarzyna Domańska for her help in preparing the time-lapse movie and Tomasz Skrzypek for SEM photography of the samples.

Conflicts of Interest: The authors declare that they have no known competing interest. The funders had no role in the design of the study; in the collection, analyses, or interpretation of data; in the writing of the manuscript, or in the decision to publish the results.

\section{References}

1. Plastics-the Facts 2020. An analysis of European Plastics Production, Demand and Waste Data. Plastics Europe, Association of Plastics Manufacturers. 2020. Available online: https://www.plasticseurope.org/download_file/force/4261/181 (accessed on 16 December 2020).

2. Jambeck, J.R.; Geyer, R.; Wilcox, C.; Siegler, T.R.; Perryman, M.; Andrady, A.; Narayan, R.; Lavender Law, K. Plastic waste inputs from land into the ocean. Science (80-) 2015, 347, 768-771. [CrossRef]

3. Kosior, E.; Mitchell, J. Current Industry Position on Plastic Production and Recycling; Elsevier Inc.: Amsterdam, The Netherlands, 2020; ISBN 9780128178805.

4. Achilias, D.S.; Roupakias, C.; Megalokonomos, P.; Lappas, A.A.; Antonakou, E.V. Chemical recycling of plastic wastes made from polyethylene (LDPE and HDPE) and polypropylene (PP). J. Hazard. Mater. 2007, 149, 536-542. [CrossRef] [PubMed] 
5. Anuar Sharuddin, S.D.; Abnisa, F.; Wan Daud, W.M.A.; Aroua, M.K. A review on pyrolysis of plastic wastes. Energy Convers. Manag. 2016, 115, 308-326. [CrossRef]

6. Chiemchaisri, C.; Charnnok, B.; Visvanathan, C. Recovery of plastic wastes from dumpsite as refuse-derived fuel and its utilization in small gasification system. Bioresour. Technol. 2010, 101, 1522-1527. [CrossRef]

7. Tokiwa, Y.; Calabia, B.P. Degradation of microbial polyesters. Biotechnol. Lett. 2004, 26, 1181-1189. [CrossRef]

8. Bhardwaj, H.; Gupta, R.; Tiwari, A. Communities of microbial enzymes associated with biodegradation of plastics. J. Polym. Environ. 2013, 21, 575-579. [CrossRef]

9. Ahmed, T.; Shahid, M.; Azeem, F.; Rasul, I.; Shah, A.A.; Noman, M.; Hameed, A.; Manzoor, N.; Manzoor, I.; Muhammad, S. Biodegradation of plastics: Current scenario and future prospects for environmental safety. Environ. Sci. Pollut. Res. 2018, 25, 7287-7298. [CrossRef]

10. Hadad, D.; Geresh, S.; Sivan, A. Biodegradation of polyethylene by the thermophilic bacterium Brevibacillus borstelensis. J. Appl. Microbiol. 2005, 98, 1093-1100. [CrossRef] [PubMed]

11. Tomita, K.; Kuroki, Y.; Nagai, K. Isolation of thermophiles degrading poly(L-lactic acid). J. Biosci. Bioeng. 1999, 87, 752-755. [CrossRef]

12. Obradors, N.; Aguilar, J. Efficient biodegradation of high-molecular-weight polyethylene glycols by pure cultures of Pseudomonas stutzeri. Appl. Environ. Microbiol. 1991, 57, 2383-2388. [CrossRef]

13. Walter, T.; Augusta, J.; Müller, R.J.; Widdecke, H.; Klein, J. Enzymatic degradation of a model polyester by lipase from Rhizopus delemar. Enzym. Microb. Technol. 1995, 17, 218-224. [CrossRef]

14. Nishide, H.; Toyota, K.; Kimura, M. Effects of soil temperature and anaerobiosis on degradation of biodegradable plastics in soil and their degrading microorganisms. Soil Sci. Plant Nutr. 1999, 45, 963-972. [CrossRef]

15. Billen, P.; Khalifa, L.; Van Gerven, F.; Tavernier, S.; Spatari, S. Technological application potential of polyethylene and polystyrene biodegradation by macro-organisms such as mealworms and wax moth larvae. Sci. Total Environ. 2020, 735, 139521. [CrossRef] [PubMed]

16. Bożek, M.; Hanus-Lorenz, B.; Rybak, J. The studies on waste biodegradation by Tenebrio molitor. E3S Web Conf. $2017,17,00011$. [CrossRef]

17. Przemieniecki, S.W.; Kosewska, A.; Ciesielski, S.; Kosewska, O. Changes in the gut microbiome and enzymatic profile of Tenebrio molitor larvae biodegrading cellulose, polyethylene and polystyrene waste. Environ. Pollut. 2020, 256, 113265. [CrossRef] [PubMed]

18. Urbanek, A.K.; Rybak, J.; Wróbel, M.; Leluk, K.; Mirończuk, A.M. A comprehensive assessment of microbiome diversity in Tenebrio molitor fed with polystyrene waste. Environ. Pollut. 2020, 262, 114281. [CrossRef] [PubMed]

19. Wu, Q.; Tao, H.; Wong, M.H. Feeding and metabolism effects of three common microplastics on Tenebrio molitor L. Environ. Geochem. Health 2019, 41, 17-26. [CrossRef]

20. Yang, Y.; Yang, J.; Wu, W.M.; Zhao, J.; Song, Y.; Gao, L.; Yang, R.; Jiang, L. Biodegradation and mineralization of polystyrene by plastic-eating mealworms: Chemical and physical characterization and isotopic tests. Environ. Sci. Technol. 2015, 49, 12080-12086. [CrossRef]

21. Yang, Y.; Wang, J.; Xia, M. Biodegradation and mineralization of polystyrene by plastic-eating superworms Zophobas atratus. Sci. Total Environ. 2020, 708, 135233. [CrossRef]

22. Aboelkheir, M.G.; Visconte, L.Y.; Oliveira, G.E.; Toledo Filho, R.D.; Souza, F.G. The biodegradative effect of Tenebrio molitor Linnaeus larvae on vulcanized SBR and tire crumb. Sci. Total Environ. 2019, 649, 1075-1082. [CrossRef]

23. Abdulhay, H.S. Biodegradation of plastic wastes by confused flour beetle Tribolium confusum Jacquelin du Val larvae. Asian J. Agric. Biol. 2020, 8, 201-206. [CrossRef]

24. Lou, Y.; Ekaterina, P.; Yang, S.S.; Lu, B.; Liu, B.; Ren, N.; Corvini, P.F.X.; Xing, D. Biodegradation of polyethylene and polystyrene by greater wax moth larvae (Galleria mellonella L.) and the effect of co-diet supplementation on the core gut microbiome. Environ. Sci. Technol. 2020, 54, 2821-2831. [CrossRef]

25. Zhang, J.; Gao, D.; Li, Q.; Zhao, Y.; Li, L.; Lin, H.; Bi, Q.; Zhao, Y. Biodegradation of polyethylene microplastic particles by the fungus Aspergillus flavus from the guts of wax moth Galleria mellonella. Sci. Total Environ. 2020, 704. [CrossRef]

26. Kesti, S.S.; Thimmappa, C.S. First report on biodegradation of low density polyethylene by rice moth larvae, Corcyra cephalonica (stainton). Holist. Approach Environ. 2019, 9, 79-83. [CrossRef]

27. Ewuim, S. Entomoremediation-A novel in-Situ bioremediation approach. Anim. Res. Int. 2013, 10, 1681-1684. [CrossRef]

28. Bulak, P.; Polakowski, C.; Nowak, K.; Waśko, A.; Wiącek, D.; Bieganowski, A. Hermetia illucens as a new and promising species for use in entomoremediation. Sci. Total Environ. 2018, 633, 912-919. [CrossRef] [PubMed]

29. Song, Y.; Qiu, R.; Hu, J.; Li, X.; Zhang, X.; Chen, Y.; Wu, W.M.; He, D. Biodegradation and disintegration of expanded polystyrene by land snails Achatina fulica. Sci. Total Environ. 2020, 746, 141289. [CrossRef] [PubMed]

30. Mariod, A.A.; Mirghani, M.E.S.; Hussein, I. Tenebrio molitor Mealworm. Unconv. Oilseeds Oil Sources 2017, 331-336. [CrossRef]

31. Finke, M.D. Complete nutrient content of four species of commercially available feeder insects fed enhanced diets during growth. Zoo Biol. 2015, 34, 554-564. [CrossRef]

32. Jajic, I.; Popovic, A.; Urosevic, M.; Krstovic, S.; Petrovic, M.; Guljas, D.; Samardzic, M. Fatty and amino acid profile of mealworm larvae (Tenebrio molitor L.). Biotechnol. Anim. Husb. 2020, 36, 167-180. [CrossRef] 
33. Jansen, Z. The Nutritional Potential of Black Soldier Fly (Hermetia Illucens) Larvae for Layer Hens. Ph.D. Thesis, Stellenbosch University, Stellenbosch, South Africa, 2018; pp. 1-103.

34. Rivero Pino, F.; Pérez Gálvez, R.; Espejo Carpio, F.J.; Guadix, E.M. Evaluation of: Tenebrio molitor protein as a source of peptides for modulating physiological processes. Food Funct. 2020, 11, 4376-4386. [CrossRef]

35. Houben, D.; Daoulas, G.; Faucon, M.P.; Dulaurent, A.M. Potential use of mealworm frass as a fertilizer: Impact on crop growth and soil properties. Sci. Rep. 2020, 10, 4659. [CrossRef] [PubMed]

36. Bulak, P.; Proc, K.; Pawłowska, M.; Kasprzycka, A.; Berus, W.; Bieganowski, A. Biogas generation from insects breeding post production wastes. J. Clean. Prod. 2020, 244, 531-537. [CrossRef]

37. Kwon, G.T.; Yuk, H.G.; Lee, S.J.; Chung, Y.H.; Jang, H.S.; Yoo, J.S.; Cho, K.H.; Kong, H.; Shin, D. Mealworm larvae (Tenebrio molitor L.) exuviae as a novel prebiotic material for BALB/c mouse gut microbiota. Food Sci. Biotechnol. 2020, $29,531-537$. [CrossRef] [PubMed]

38. Dabbou, S.; Ferrocino, I.; Gasco, L.; Schiavone, A.; Trocino, A.; Xiccato, G.; Barroeta, A.C.; Maione, S.; Soglia, D.; Biasato, I.; et al. Antimicrobial effects of black soldier fly and yellow mealworm fats and their impact on gut microbiota of growing rabbits. Animals 2020, 10, 1292. [CrossRef] [PubMed]

39. Saenz-Mendoza, A.I.; Zamudio-Flores, P.B.; García-Anaya, M.C.; Velasco, C.R.; Acosta-Muñiz, C.H.; de Jesús Ornelas-Paz, J.; Hernández-González, M.; Vargas-Torres, A.; Aguilar-González, M.Á.; Salgado-Delgado, R. Characterization of insect chitosan films from Tenebrio molitor and Brachystola magna and its comparison with commercial chitosan of different molecular weights. Int. J. Biol. Macromol. 2020, 160, 953-963. [CrossRef]

40. Li, X.; Chen, L.; Mei, Q.; Dong, B.; Dai, X.; Ding, G.; Zeng, E.Y. Microplastics in sewage sludge from the wastewater treatment plants in China. Water Res. 2018, 142, 75-85. [CrossRef]

41. Yang, S.S.; Brandon, A.M.; Andrew Flanagan, J.C.; Yang, J.; Ning, D.; Cai, S.Y.; Fan, H.Q.; Wang, Z.Y.; Ren, J.; Benbow, E.; et al Biodegradation of polystyrene wastes in yellow mealworms (larvae of Tenebrio molitor Linnaeus): Factors affecting biodegradation rates and the ability of polystyrene-fed larvae to complete their life cycle. Chemosphere 2018, 191, 979-989. [CrossRef]

42. Peng, B.Y.; Su, Y.; Chen, Z.; Chen, J.; Zhou, X.; Benbow, M.E.; Criddle, C.S.; Wu, W.M.; Zhang, Y. Biodegradation of polystyrene by Dark (Tenebrio obscurus) and Yellow (Tenebrio molitor) Mealworms (Coleoptera: Tenebrionidae). Environ. Sci. Technol. 2019, 53, 5256-5265. [CrossRef]

43. Brandon, A.M.; Gao, S.H.; Tian, R.; Ning, D.; Yang, S.S.; Zhou, J.; Wu, W.M.; Criddle, C.S. Biodegradation of polyethylene and plastic mixtures in mealworms (larvae of Tenebrio molitor) and effects on the gut microbiome. Environ. Sci. Technol. 2018, 52, 6526-6533. [CrossRef]

44. Guo, B.; Yin, J.; Hao, W.; Jiao, M. Polyurethane foam induces epigenetic modification of mitochondrial DNA during different metamorphic stages of Tenebrio molitor. Ecotoxicol. Environ. Saf. 2019, 183, 109461. [CrossRef]

45. Khan, S.; Nadir, S.; Mortimer, P.E.; Xu, J.; Gui, H.; Khan, A.; Iqbal, S.; Ye, L.; Shi, L. Biodegradation of polyester polyurethane by Aspergillus tubingensis. Environ. Pollut. 2019, 229, 469-480. [CrossRef] [PubMed]

46. Yang, L.; Gao, J.; Liu, Y.; Zhuang, G.; Peng, X.; Wu, W.M.; Zhuang, X. Biodegradation of expanded polystyrene and lowdensity polyethylene foams in larvae of Tenebrio molitor Linnaeus (Coleoptera: Tenebrionidae): Broad versus limited extent depolymerization and microbe-dependence versus independence. Chemosphere 2021, 262, 127818. [CrossRef] [PubMed]

47. Yang, S.S.; Wu, W.M.; Brandon, A.M.; Fan, H.Q.; Receveur, J.P.; Li, Y.; Wang, Z.Y.; Fan, R.; McClellan, R.L.; Gao, S.H.; et al. Ubiquity of polystyrene digestion and biodegradation within yellow mealworms, larvae of Tenebrio molitor Linnaeus (Coleoptera: Tenebrionidae). Chemosphere 2018, 212, 262-271. [CrossRef] [PubMed]

48. Ranta-Korpi, M.; Vainikka, P.; Konttinen, J.; Saarimaa, A.; Rodriguez, M. Ash Forming Elements in Plastics and Rubbers; VTT Technical Research Centre of Finland: Espoo, Finland, 2014; ISBN 978-951-38-8158-0.

49. Turner, A. Heavy metals, metalloids and other hazardous elements in marine plastic litter. Mar. Pollut. Bull. 2016, 111, 136-142. [CrossRef]

50. Sing, H.; Jain, A. Ignition, combustion, toxicity, and fire retardancy of polyurethane foams: A comprehensive review. J. Appl. Polym. Sci. 2008, 111, 1115-1143. [CrossRef]

51. Alt, H.G.; Samuel, E. Fluorenyl complexes of zirconium and hafnium as catalysts for olefin polymerization. Chem. Soc. Rev. 1998, 27, 323-329. [CrossRef]

52. Lee, H.M.; Kim, H.R.; Jeon, E.; Yu, H.C.; Lee, S.; Li, J.; Kim, D.-H. Evaluation of the biodegradation efficiency of four various types of plastics by Pseudomonas aeruginosa isolated from the gut extract of superworms. Microorganisms 2020, 8, 1341. [CrossRef]

53. Masykuri, M.; Widyasari, F. Surface morphology and biodegradation tests of polyurethane/clay rigid foam composites. J. Chem. Technol. Metall. 2021, 56, 744-753.

54. Ichikawa, T.; Kurauchi, T. Larval cannibalism and pupal defense against cannibalism in two species of tenebrionid beetles. Zool. Sci. 2009, 26, 525-529. [CrossRef] 